\title{
Crosses between sexual and apomictic dandelions (Taraxacum). II. The breakdown of apomixis
}

\author{
PETER J. VAN DIJK*, INGE C. Q. TAS, \\ MATTHIEU FALQUE $\uparrow \&$ TANJA BAKX-SCHOTMAN \\ Department of Plant Population Biology, Netherlands Institute of Ecology, Center for Terrestrial Ecology \\ (NIOO-CTO), PO Box 40, 6666 ZG Heteren, The Netherlands, †INRA-UPS-CNRS-URA 1492, Station de génétique \\ végétale, Ferme du Moulon, F-91190 Gif-sur-Yuette, France
}

\begin{abstract}
Some dandelions are diplosporous gametophytic apomicts. In order to study the inheritance and breakdown of apomixis, crosses were made between diploid sexuals and triploid apomicts. To investigate their breeding system, four nonapomictic diploid and 10 nonapomictic triploid hybrids were pollinated with diploids and the progenies were analysed. Seed fertility was significantly reduced in two diploid hybrids. Nine triploid hybrids were fertile and could be classified into three types, with respect to the composition of their progenies. Type A produced $n+n$ hybrids. Type $\mathrm{B}$ produced either a mixture of $n+n$ and $2 n+n$ hybrids, or a mixture of pseudogamous $2 n+0$ apomicts and $2 n+n$ hybrids. Type $\mathrm{C}$ produced exclusively $2 n+n$ hybrids. Inheritance of a microsatellite marker strongly suggested that $2 n$ egg cells in type $\mathrm{C}$ plants were produced by a first division restitution mechanism. As in apomicts, microsporogenesis in type $\mathrm{C}$ plants was reductional. This suggests that type $\mathrm{C}$ plants are diplosporous plants that lack parthenogenesis. Such plants are very rare in other apomictic plant species. It is concluded that 'elements of apomixis', diplospory and parthenogenesis, can be uncoupled. This is inconsistent with the single-locus model for apomixis in Taraxacum as suggested by Mogie (1992). Instead, our results suggest that several loci are involved in the genetic control of apomixis in Taraxacum.
\end{abstract}

Keywords: $2 n$-gametes, apomixis, diplospory, parthenogenesis, pseudogamy, Taraxacum.

\section{Introduction}

In apomictic plants seeds are produced asexually (Nogler, 1984; Asker \& Jerling, 1992; Mogie, 1992; Koltunow, 1993). Apomictic seed development differs in at least three elements from sexual seed development: (i) avoidance of meiotic reduction; (ii) avoidance of fertilization; and (iii) parthenogenetic embryo development. This results in the production of $2 n+0$ maternal offspring, instead of $n+n$ sexual offspring (using the terminology of Harlan \& DeWet, 1975). In most apomicts, the endosperm is formed sexually, after fertilization of the central cell of the embryo sac (pseudogamy). In autonomous apomicts, such as dandelions, Taraxacum, however, the endosperm develops autonomously. In this paper we report on the breakdown of apomixis in Taraxacum into its elements.

*Correspondence. Email: pjvandijk@cto.nioo.knaw.nl

(C) 1999 The Genetical Society of Great Britain.
Apomixis is a complex developmental trait and the prevailing opinion has for long been that the elements of apomixis are controlled by independent genes. In order to understand the genetics of apomixis, these elements should be analysed separately in crosses (Asker, 1980; Nogler, 1984). However, the extreme rarity of apomictic recombinants (either producing exclusively $2 n+n$ hybrids or producing exclusively $n+0$ polyhaploids) has raised doubts about the independent genetic control of elements of apomixis (Asker \& Jerling, 1992). In their monograph on apomixis in plants, Asker \& Jerling (1992) cite only three cases of plants producing exclusively $2 n+n$ hybrids: Parthenium argentatum (Powers, 1945), Potentilla argentea (Asker, 1970) and Ranunculus auricomus (Nogler, 1984). Further investigations of a putative apomictic recombinant in $R$. auricomus, however, made clear that this plant was in fact an apomict, but that parthenogenetic development was initiated so late that fertilization predominated in crosses (Nogler, 1995). 
In Taraxacum both single- and two-locus controls of apomixis have been proposed (Richards, 1970, 1973; Mogie, 1992). Diploids $(2 n=2 \mathrm{x}=16)$ are sexual, and polyploids, mainly triploids $(2 n=3 \mathrm{x}=24)$, are apomicts. In apomictic dandelions, a first division restitution (FDR), followed by a normal second meiotic division produces two unreduced megaspores (diplospory). The micropylar megaspore dies and gametogenesis of the unreduced chalazal megaspore leads to the formation of an unreduced megagametophyte or embryo sac. In apomicts, this unreduced embryo sac matures precociously and the unreduced egg cell develops parthenogenetically into the embryo. The central cell of the unreduced embryo sac develops autonomously into the endosperm. Parthenogenetic embryogenesis in apomicts proceeds $36-48 \mathrm{~h}$ before anthesis, thereby preventing fertilization (Richards, 1973).

Sørensen (1958) reported that the loss of certain chromosomes induced partial sexuality in triploid obligate apomictic lineages of Taraxacum. He identified two nonhomologous chromosomes, lacking in the aberrants tenuis and elegans, with different sexuality-inducing effects. Based on this work, Richards (1970, 1973) developed a model in which apomixis in Taraxacum was controlled by two unlinked dominant genes: one for diplospory and a second for parthenogenesis. However, this two-locus model has been challenged by Mogie (1992) because of the insufficient quality of Sørensen's data: the unreliable karyology and the small and heterogeneous progenies. Instead, Mogie proposed a single-locus recessive model in which parthenogenesis is a pleiotropic effect of diplospory. In this model diplospory is an abbreviated, shortened form of meiosis, consequently leading to precocious maturation of the embryo sac. In turn, precocious embryo sac maturation induces parthenogenetic development of embryo and endosperm.

Microsporogenesis in Taraxacum is reductional, in contrast to megasporogenesis which is restitutional. Therefore recombination of elements of apomixis can be studied in crosses using apomictic plants as pollen donors. If apomixis in Taraxacum is controlled by multiple heterozygous loci it should be possible to find apomictic recombinants in crosses, unless these loci are tightly linked. Such recombinants would be nonapomictic. In an accompanying paper (Tas \& van Dijk, 1999), we reported on the inheritance of apomixis in sexual $\times$ apomictic crosses. All the diploid hybrids and two-thirds of the triploid hybrids obtained in these crosses were nonapomicts. In this paper we report on the mode of reproduction in these nonapomictic hybrids. It is shown that some of the hybrids can be interpreted as apomictic recombinants. We suggest that seed development in these apomictic recombinants resembles the different types of seed development observed by Malecka (1973) in individual ovules of facultative apomictic $T$. palustre. Both studies support a multigenic control of apomixis in Taraxacum.

\section{Materials and methods}

The crosses between diploid sexual and triploid apomictic dandelions from the section Ruderalia have been described in Tas \& Van Dijk (1999). Details about growing conditions and crossing techniques can also be found in that paper. Emasculation tests showed that none of the four diploid hybrids (H2-1, 3-3, 3-8 and 4-1) could reproduce apomictically. Likewise, 10 of the 15 triploid hybrids could not reproduce apomictically (H2-3, 2-4, 3-1 3-4, 3-5, 3-6, 3-7, 3-9, 6-3 and 6-4).

To investigate the mode of reproduction in these nonapomictic hybrids, all hybrids were pollinated with diploids. As a control, the spontaneous seed production was checked on flower heads that were covered with paper bags to prevent cross-pollination. Seed-set and germination rate were determined as described in Tas \& Van Dijk (1999). Because pollen meiosis in diploids is regular, the diploid pollen donor will contribute eight chromosomes to the offspring in the hybrid $\times$ diploid crosses. The chromosome number of the fertilized egg cell of the seed parent can thus be determined by subtraction of eight chromosomes from the chromosome number of the progeny. Chromosome numbers were determined indirectly by measuring the relative amount of nuclear DNA by flow cytometry (PARTEC Ploidy Analyser; Tas \& Van Dijk, 1999). To investigate the mode of reproduction of H6-3 in more detail, the inheritance of a microsatellite marker, msta72, was studied. Mendelian inheritance for this marker has been confirmed in sexual crosses. DNA isolation methods, microsatellite amplification and detection were carried out according to the procedures described in Falque et al. (1998).

\section{Results}

\section{Seed development after isolation}

The emasculation test classified all plants here as nonapomictic (Tas \& Van Dijk, 1999). When isolated from cross-pollination, as expected, seed-set in the four diploid hybrids was zero. In contrast, some of the nonapomictic triploids produced low numbers of welldeveloped seeds on bagged flowers (Table 1). This spontaneous seed-set was highest in H3-9, up to 0.24. 
Table 1 Spontaneous seed-set on bagged flowers of triploid nonapomictic hybrid Taraxacum. The progeny type refers to progeny types that are produced after crosspollination with diploids (see Table 3)

\begin{tabular}{lcccccc}
\hline $\begin{array}{l}3 \mathrm{x} \\
\text { hybrid }\end{array}$ & $\begin{array}{c}\text { Mean } \\
\text { seed-set } \pm \text { SE }\end{array}$ & $\begin{array}{c}\text { No. seed } \\
\text { heads }\end{array}$ & $\begin{array}{c}\text { Seed-set } \\
\text { range }\end{array}$ & $\begin{array}{c}\text { Germination } \\
\text { rate }\end{array}$ & $\begin{array}{c}\text { No. seeds } \\
\text { tested }\end{array}$ & $\begin{array}{c}\text { Progeny } \\
\text { type }\end{array}$ \\
\hline $3-4$ & 0.00 & 5 & 0.00 & - & - & - \\
$2-3$ & 0.00 & 2 & 0.00 & - & - & A? \\
$2-4$ & $0.00 \pm 0.00$ & 2 & 0.00 & - & - & A \\
$3-5$ & 0.00 & 1 & - & - & - & $\mathrm{A}$ \\
$3-6$ & $0.01 \pm 0.01$ & 2 & $0.00-0.02$ & 0.00 & 4 & $\mathrm{~B}$ \\
$3-7$ & $0.01 \pm 0.01$ & 2 & $0.01-0.02$ & 0.00 & 4 & $\mathrm{~B}$ \\
$6-4$ & $0.02 \pm 0.00$ & 2 & $0.02-0.02$ & 0.00 & 9 & $\mathrm{~B}$ \\
$3-1$ & $0.04 \pm 0.00$ & 2 & $0.04-0.04$ & 0.00 & 17 & $\mathrm{~B}$ \\
$6-3$ & $0.07 \pm 0.03$ & 3 & $0.03-0.13$ & 0.00 & 45 & $\mathrm{C}$ \\
$3-9$ & $0.14 \pm 0.02$ & 5 & $0.08-0.24$ & 0.00 & 50 & $\mathrm{C}$ \\
\hline
\end{tabular}

However, none of the seeds produced under isolation germinated (Table 1). Dissecting under a dissecting microscope showed that they were invariably empty; embryos were always absent.

\section{Seed development after cross-pollination}

Table 2 gives the seed-sets and germination rates of hybrid plants when cross-pollinated with diploid plants.

Table 2 Seed production in nonapomictic diploid and triploid hybrid Taraxacum after pollination with diploid sexual plants. Because of the variable number of receptive florets at crossing, seed-set is highly variable between seed heads of the same plant (Tas \& Van Dijk, 1999). Therefore, for each hybrid the seed head with the highest seed-set is given (out of three to five). The viable seed-set is the product of seed-set and germination rate

\begin{tabular}{|c|c|c|c|c|}
\hline Hybrid & Seed-set & $\begin{array}{l}\text { Germination } \\
\text { rate }\end{array}$ & $\begin{array}{c}\text { Viable } \\
\text { seed-set }\end{array}$ & $\begin{array}{c}\text { Progeny } \\
\text { type }\end{array}$ \\
\hline \multicolumn{5}{|l|}{ Diploids } \\
\hline $2-1$ & 0.53 & 1.00 & 0.53 & - \\
\hline $3-3$ & 0.36 & 0.16 & 0.06 & - \\
\hline $3-8$ & 0.68 & 0.84 & 0.56 & - \\
\hline 4-1 & 0.47 & 0.52 & 0.24 & - \\
\hline \multicolumn{5}{|l|}{ Triploids } \\
\hline $2-3$ & 0.19 & 0.00 & 0.00 & $\mathrm{~A}$ ? \\
\hline $3-4$ & 0.00 & - & 0.00 & - \\
\hline $2-4$ & 0.36 & 0.12 & 0.04 & A \\
\hline $3-1$ & 0.39 & 0.36 & 0.14 & B \\
\hline $3-5$ & 0.23 & 0.36 & 0.08 & A \\
\hline $3-6$ & 0.19 & 0.80 & 0.15 & B \\
\hline $3-7$ & 0.20 & 0.56 & 0.11 & B \\
\hline $3-9$ & 0.74 & 0.76 & 0.56 & $\mathrm{C}$ \\
\hline $6-3$ & 0.69 & 0.29 & 0.20 & $\mathrm{C}$ \\
\hline $6-4$ & 0.23 & 0.36 & 0.08 & B \\
\hline
\end{tabular}

Viable seed-set in two of the diploid hybrids (H4-1 and 3-3) was significantly lower than in the other two (H2-1 and 3-8). Cytological analysis revealed that the $F_{2}$ progenies of the diploid hybrids were completely diploid (Table 3).

Seed-set when triploid sexual hybrids were crossed with diploid pollen donors was variable, but in general low (Table 2). Two triploid hybrids produced no viable offspring after cross-pollination. H3-4 did not develop any seeds after crossing. In contrast, $19 \%$ of the seeds of H2-3 developed after cross-pollination, but none of these germinated. In general, apparently well developed, but nongerminating seeds contained small, poorly developed embryos. Completely empty seeds, as were produced on flowers that were bagged, were rare.

The cytogenetic analysis of viable offspring is summarized in Table 3. The chromosome numbers in the progeny ranged from 16 to 32 and the inferred egg cell chromosome numbers, after subtraction of the eight paternal chromosomes, from reduced haploid $(n=\mathrm{x}=8)$ to unreduced triploid $(2 n=3 \mathrm{x}=24)$.

Although the number of offspring per mother plant that was available for cytological analysis was small in most cases, three types can be distinguished on the basis of their progeny composition.

Type A (H2-4 and 3-5) produced progenies with the lowest chromosome numbers, ranging from 16 to 23 (Table 3). Tetraploid offspring were not found, but the sample sizes were small.

Type B (H3-1, 3-6, 3-7 and 6-4) produced progenies with higher chromosome numbers than produced by type A, ranging from 22 to 32 . Despite the considerable sample size, no diploid $(2 n=16)$ offspring were found in this type. Overall, $29.4 \%$ of the triploids and $30 \%$ of the tetraploid offspring were hypo-euploid.

Type $\mathrm{C}$ (H3-9 and 6-3) produced cross progenies that were entirely (near-) tetraploid $(2 n=4 \mathrm{x}=32)$. Taken 
Table 3 Cytological analyses of the progenies obtained after pollinating the hybrid Taraxacum with diploid pollen donors. $2 n$ refers to the somatic chromosome number of the offspring. $2 n$ minus 8 refers to the chromosome number of the fertilized egg cell

\begin{tabular}{|c|c|c|c|c|c|c|c|c|c|c|c|c|c|c|c|c|c|c|}
\hline \multicolumn{19}{|c|}{ Chromosome numbers in $\mathrm{F}_{2}$} \\
\hline $2 n$ & 16 & 17 & 18 & 19 & 20 & 21 & 22 & 23 & 24 & 25 & 26 & 27 & 28 & 29 & 30 & 31 & 32 & \\
\hline $2 n$ minus 8 & 8 & 9 & 10 & 11 & 12 & 13 & 14 & 15 & 16 & 17 & 18 & 19 & 20 & 21 & 22 & 23 & 24 & Total \\
\hline \multicolumn{19}{|l|}{$2 x$ hybrids } \\
\hline $2-1$ & 25 & - & - & - & - & - & - & - & - & - & - & - & - & - & - & - & - & 25 \\
\hline $3-3$ & 18 & - & - & - & - & - & - & - & - & - & - & - & - & - & - & - & - & 18 \\
\hline $3-8$ & 25 & - & - & - & - & - & - & - & - & - & - & - & - & - & - & - & - & 25 \\
\hline $4-1$ & 21 & - & - & - & - & - & - & - & - & - & - & - & - & - & - & - & - & 21 \\
\hline \multicolumn{19}{|l|}{$3 x$ type $A$} \\
\hline $2-4$ & 1 & - & - & - & - & - & - & 1 & - & - & - & - & - & - & - & - & - & 2 \\
\hline $3-5$ & 1 & 1 & - & 1 & - & 3 & 一 & - & - & - & - & - & - & - & - & - & - & 6 \\
\hline \multicolumn{19}{|l|}{$3 x$ type $B$} \\
\hline $3-1$ & - & - & - & - & - & - & 2 & 2 & 3 & - & - & - & - & - & - & - & 2 & 9 \\
\hline $3-6$ & - & - & - & - & - & - & 1 & 2 & 8 & - & - & - & - & - & 1 & 1 & 3 & 16 \\
\hline $3-7$ & - & - & - & - & - & - & 1 & 2 & 8 & - & - & - & - & - & 1 & - & 1 & 13 \\
\hline $6-4$ & - & - & - & - & - & - & - & - & 5 & - & - & - & - & - & - & - & - & 5 \\
\hline \multicolumn{19}{|l|}{$3 x$ type $C$} \\
\hline & - & - & - & - & - & - & - & - & - & - & - & - & - & - & - & 1 & 16 & 17 \\
\hline $6-3$ & - & - & - & - & - & - & - & - & - & - & - & - & - & - & 1 & 1 & 33 & 35 \\
\hline
\end{tabular}

together, $5.8 \%$ of the offspring were hypotetraploid, the rest eutetraploid.

The three types showed different degrees of spontaneous seed development after flowers were bagged. In type A, seed heads did not expand and no seeds were produced (Table 1). On the basis of spontaneous seed development these plants could not be distinguished from sexual diploids. In type B, spontaneous seed head expansion was observed and low numbers of apparently good, but empty, seeds were produced. In type $\mathrm{C}$ there was a clear spontaneous seed head expansion and these plants produced the highest percentage of apparently good, but empty, seeds.

\section{Inheritance of a microsatellite marker in a sexual diplosporous plant H6-3}

The cytological analysis revealed that H6-3 (type C) produced exclusively tetraploid progeny, suggesting the production of $2 n+n, 3 \mathrm{x}+\mathrm{x}$ hybrids. To investigate the mechanism of $2 n, 3 \mathrm{x}$ egg cell production, the inheritance of the microsatellite marker msta72 was studied. One hundred and twenty seeds were germinated, which yielded only 35 seedlings ( $29 \%)$.

Figure 1 shows the parental genotypes and the segregation in the offspring. The parents shared no alleles and the contribution of the ovule and pollen grain in the zygote can thus be inferred unambiguously. The triploid female parent H6-3 is a triallelic heterozygote (lane 37, 173/184/188 bp), whereas the diploid male parent is a diallelic heterozygote (lane $36,176 / 202 \mathrm{bp}$ ). The inheritance of msta 72 confirms the conclusion from 6-pgd-2 electrophoresis (Tas \& Van Dijk, 1999) that H6-3 originates from a haploid egg cell from its diploid sexual mother (lane 39, 173/173 bp) and a diploid pollen grain from its triploid apomictic father (lane 38, 178/ $184 / 188 \mathrm{bp}$ ).

msta 72 amplification failed in one progeny plant (lane $30)$. The remainder of the progeny carried one of the two alleles of the pollen parent, confirming that they originated from sexual fertilization and not from parthenogenesis. Twenty plants carried the 202 bp paternal allele, 14 the $176 \mathrm{bp}$ paternal allele. This is not a significant departure from the expected 1:1 segregation ratio $\left(\chi_{1}^{2}=1.06 ; P>0.30\right)$.

All except one of the 34 offspring that amplified, inherited the full maternal triallelic heterozygous genotype. The plant in lane 6 lacked one of the maternal alleles $(184 \mathrm{bp})$. Flow cytometry indicated that this plant lacked two chromosomes $(2 n=30)$, probably one of them containing the msta72 locus. Conversely, the plant in lane 13 lacked one chromosome $(2 n=31)$, but not the msta72 locus, because it had all three maternal alleles. The plant in lane 25 shows an additional, nonparental band (190 bp). As this plant is a eutetraploid and carries the maternal and the paternal msta72 


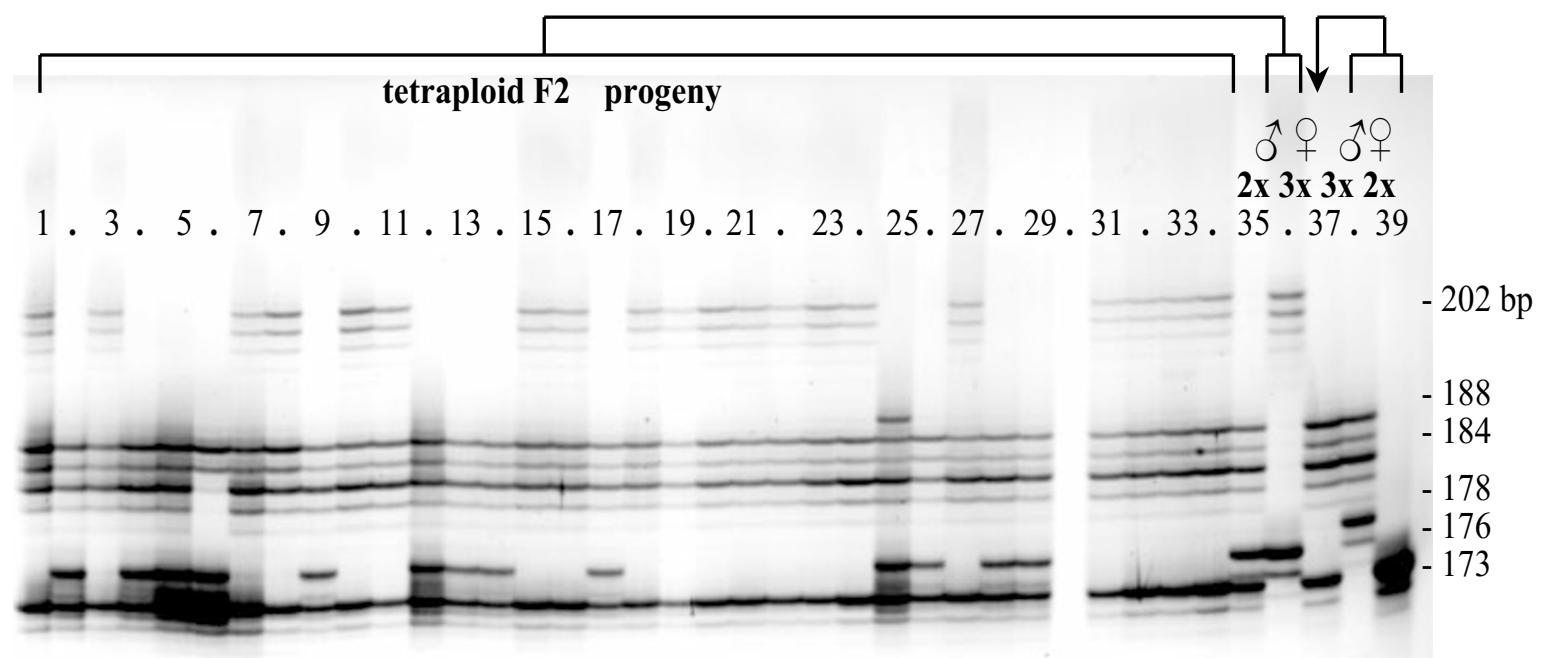

Fig. 1 Partial segregation of microsatellite marker msta72 in the Taraxacum cross H6-3 (triploid) $\times$ B12 (diploid). The triploid hybrid H6-3 is in lane 37 (173/184/188 bp), its triploid apomictic father in lane 38 (178/184/188 bp) and its diploid sexual mother in lane 39 (173/173 bp). In lane 36 is the diploid pollen donor B12 (176/202 bp). Lanes 1-35 show some of the tetraploid progeny of H6-3 $\times$ B12, which segregate for the two B12 alleles, but not for the three H6-3 alleles. There was no PCR-product in lane 30 .

complement, the most likely explanation for this extra band is a PCR artefact.

\section{Discussion}

\section{Reproduction in diploid hybrids}

The viable seed-set in two diploid hybrids was comparable to that of natural diploids. In two others it was clearly reduced. This could reflect the inheritance of a genetic load from their apomictic fathers, as asexual lineages are expected to accumulate slightly deleterious mutations over time (Muller, 1964; Kondrashov, 1982). Embryological observations, however, indicate that during megasporogenesis in $\mathrm{H} 3-3$ besides tetrads, dyads are frequently produced (P. van Baarlen, pers. comm.). Because the viable offspring from H3-3 are diploid, unreduced megaspores do not apparently develop into functional megagametophytes. This is consistent with a viable seed-set of only $6 \%$. This suggests that this diploid hybrid has inherited elements of apomixis from its apomictic father.

\section{Fertility of triploid hybrids}

In general the viable seed-set on nonapomictic triploid hybrids after cross-pollination was low, with the exception of H3-9. In the other hybrids, either the percentage of developed seeds or the germination rate, or both, are reduced in comparison to the diploid sexual and triploid apomictic parents. One of the triploid hybrids was completely seed-sterile. Future embryological investigations may reveal if this plant expressed elements of apomixis or not. In the other triploid hybrids (cyto-) genetic investigations of viable progenies gave information about their origins.

\section{Triploid hybrids with progeny type $A$}

Plants of type A had the lowest viable seed-set after crossing. Assuming that the diploid pollen donors contributed eight chromosomes to the offspring, plants of type A produced reduced egg cells ranging from $n=8$ to $n=15$, that were fertilized. Megasporogenesis in H2-4 and 3-5 was thus reductional, similar to microsporogenesis. Like microsporogenesis, this reductional megasporogenesis in triploids should be highly disturbed, producing high frequencies of unbalanced egg cells. This probably explains the low percentage of viable seeds produced by these plants. Hybrid 2-3 which produced after crossing 19\% well developed, but nonviable, seeds may also be a triploid with reductional megasporogenesis. Sørensen (1958) reported a similar change from diplospory to reductional megasporogenesis after loss of a chromosome in one of his tenuis disomics $(2 n=23)$. 


\section{Triploid hybrids with progeny type $B$}

Viable seed-set after crossing triploid plants from type B was intermediate between that of types A and C. No diploid offspring were produced, only (near-) triploid and (near-) tetraploid offspring. The percentage of aneuploid offspring was relatively high, about $33 \%$.

Sørensen (1958) described a second chromosome aberrant $(2 n=23)$, elegans, in which loss of a chromosome caused a switch from obligate to facultative apomixis. Sexual progenies of such elegans aberrants were a mixture of triploid and tetraploid plants, thus closely resembling our type B progenies.

There are two possible explanations for the mixed ploidy levels in the progenies of type B plants. First, it is possible that the triploid offspring arose by parthenogenetic development of the $2 n, 3 x$ egg cell and sexual endosperm development (pseudogamy; single fertilization), whereas the tetraploid progeny arose by double fertilization of the $2 n, 3 \mathrm{x}$ egg cell and the central cell. Cyto-embryological investigations of facultative apomixis in the section Palustria show that pseudogamy and double fertilization can co-occur on the same plant (Malecka, 1973).

Alternatively, both triploid and tetraploid offspring arose from fertilized, reduced egg cells, the eggs being $n$, $2 \mathrm{x}$ and $2 n, 3 \mathrm{x}$, respectively. In a reductional meiosis, besides $n, 2 \mathrm{x}$ egg cells, also $n$, $\mathrm{x}$ egg cells would be formed. Absence of diploid offspring could be caused by selection against haploid egg cells because of a genetic load or by segregation biased towards diploid egg cells. Secondary associations of chromosomes during megasporogenesis, which may result in biased segregation, have been described in Taraxacum by Gustafsson (1935).

To be able to distinguish between these different explanations for the origin of the type B progenies it is necessary to utilize genetic markers for the determination of the progeny genotypes.

\section{Triploid hybrids with progeny type $C$}

Triploid plants from type $\mathrm{C}$ produced exclusively tetraploid offspring after crossing with a diploid. Unreduced triploid egg cells were fertilized by haploid pollen. Sørensen (1958) did not report a chromosome aberrant with a similar reproductive behaviour as our type $\mathrm{C}$ hybrids.

In apomictic Taraxacum, $2 n$ egg cells are produced by first division restitution (FDR) (Gustafsson, 1946; Fagerlind, 1947; Battaglia, 1948). Meiosis is generally desynaptic. The full transmission of triallelic heterozygosity for msta72 in H6-3 is highly indicative for a FDR mechanism, with little or no recombination between the centromere and the marker locus (Mendiburu \&
Peloquin, 1979; Ramanna, 1979). In the case of second division restitution in all 34 first meiotic divisions, a crossing-over between the centromere and the marker locus must have occurred, which is highly unlikely. This suggests that H6-3 (and H3-9) are diplosporous plants that lack the capacity of parthenogenetic seed development. This is supported by the fact that the rate of production of aneuploid $2 n$ egg cells in type C plants, $5.8 \%$, is close to that in the apomictic triploid hybrids (5.0\%; Tas \& Van Dijk, 1999). Moreover, as in apomicts, microsporogenesis in plants of type $\mathrm{C}$ is reductional and thus not affected (P. van Dijk, unpubl. obs.).

Cyto-embryological investigations show that, in the absence of cross-pollination, one day after flowering the egg cells of H6-3 still have not divided (P. van Baarlen, pers. comm.). Therefore parthenogenesis indeed appears to be absent in H6-3 and not delayed, as was later found in a putative apomictic recombinant in $R$. auricomus (Nogler, 1995). Interestingly, the undivided egg cells in H6-3 were surrounded by multinuclear endosperm, indicating that endosperm development in H6-3 was autonomous. Thus autonomous endosperm development and parthenogenetic embryo development are uncoupled in H6-3. In Arabidopsis the fertilizationindependent endosperm (fie) and fertilization-independent seed (fis) mutations initiate autonomous endosperm and seed coat development (Ohad et al., 1996; Chaudhury et al., 1997). These mutants do not have autonomous embryo development, indicating that the initiation of embryo and endosperm development are controlled by different genes in Arabidopsis. Autonomous endosperm development in type $\mathrm{C}$ plants may have induced seed coat and fruit development, thereby explaining the occurrence of parthenocarpy on bagged flowers in these plants.

\section{The genetic control of apomixis in Taraxacum}

Richards $(1970,1973)$ explained the loss of diplospory in one of Sørensen's tenuis aberrants by the loss of a chromosome carrying a dominant allele for diplospory. Our type A triploids may have inherited nondiplosporous alleles from the apomictic fathers because of the segregation of the diplospory genotype during reductional pollen meiosis. Richards $(1970,1973)$ assumed that loss of another chromosome in Sørensen's elegans aberrants caused the loss of parthenogenesis. Therefore he postulated a second dominant apomixis gene for parthenogenetic embryo development. Mogie (1992) criticized this interpretation because the elegans aberrants produced both reduced and unreduced egg cells (as did our type B plants) and could therefore not be considered as diplosporous plants lacking parthenogenesis. However, the type $\mathrm{C}$ plants, found in this study, are good candidates for such apomictic recombinants. 
We presume that recombination occurred during reductional pollen meiosis in the father apomicts. The occurrence of type $\mathrm{C}$ plants is incompatible with Mogie's (1992) model of single-locus control of apomixis in Taraxacum.

Interestingly, Malecka (1973) described reproductive phenomena similar to those found in type $\mathrm{C}$ plants in facultative apomictic Taraxacum section Palustria. Cyto-embryological investigations showed that occasionally precocious parthenogenetic embryos as well as delayed $2 n$ egg cells co-occurred within a single flower head. Such delayed $2 n$ egg cells could be fertilized at anthesis, giving rise to $2 n+n$ hybrids, as in type $\mathrm{C}$ plants. Malecka also reported the uncoupling of parthenogenetic embryo development and autonomous endosperm development as well as the production of apparently normal but empty seeds. Loss of parthenogenetic embryo development was correlated to chromosome pairing during megasporogenesis. Therefore, Malecka (1973) explained the loss of parthenogenesis by occasional crossing-over during diplosporic megasporogenesis ('subsexual processes', Darlington, 1937; 'auto-segregation', Gustafsson, 1946). In the case of facultative apomictic Taraxacum section Palustria the breakdown of apomixis into its elements occurred at the ovule level within a single flower head. In our case of obligate apomictic Taraxacum section Ruderalia, the breakdown occurred at the plant level, between hybrid progeny within crosses. The former can be explained by recombination during restitutional megasporogenesis, the latter by recombination during reductional microsporogenesis. Both cases suggest a multigenic control of apomixis in Taraxacum.

\section{Acknowledgements}

We are grateful to Peter van Baarlen for providing unpublished information on the embryology of some of the hybrids and to two anonymous reviewers for their comments.

\section{References}

ASKer, S. 1970. Apomixis and sexuality in the Potentilla argentea complex II. Crosses within the complex. Hereditas, 66, 189-204.

ASKER, s. 1980. Gametophytic apomixis: elements and genetic regulation. Hereditas, 93, 277-293.

ASKer, S. E. AND Jerling, L. 1992. Apomixis in Plants. CRC Press, Boca Raton, FL.

BAtTAgliA, E. 1948. Ricerche sulla parameiosi restituzionale nel genere Taraxacum. Caryologia, 1, 1-47.

CHAUdhury, A. M., MING, L., MILleR, C., CRAIG, S., DENNIS, E. S. AND PEACOCK, W. J. 1997. Fertilization-independent seed development in Arabidopsis thaliana. Proc. Natl. Acad. Sci. U.S.A., 94, 4223-4228.

DARLington, C. D. 1937. Recent Advances in Cytology, 2nd edn. Churchill, London.

FAGERLIND, F. 1947. Makrosporogenesis und embryosackbildung bei agamospermischen Taraxacum-biotypen. Bot. Tidskr., 41, 365-390.

FALQUE, M., KEURENTJES, J., BAKX-SCHOTMAN, J. M. T. AND VAN DIJK, P. J. 1998. Development and characterization of microsatellite markers in the sexual-apomictic complex Taraxacum officinale (dandelion). Theor. Appl. Genet., 97, 283-292.

GUSTAFSSON, A. 1935. Primary and secondary association in Taraxacum. Hereditas, 20, 1-31.

Gustafsson, A. 1946. Apomixis in higher plants. Part I. The mechanisms of apomixis. Lunds Univ. Arsskr., N.F.Avd., 42, $1-66$.

HARLAN, J. R. AND DEWET, J. M. J. 1975. On Ö. Winge and a prayer: The origins of polyploidy. Bot. Rev., 41, 361-390.

Koltunow, A. M. 1993. Apomixis: embryo sacs and embryos formed without meiosis or fertilization in ovules. Pl. Cell, $\mathbf{5}$, 1425-1437.

KONDRASHOV, A. S. 1982. Selection against harmful mutations in large sexual and asexual populations. Genet. Res., 40, 325-332.

MALECKA, J. 1973. Problems of the mode of reproduction in microspecies of Taraxacum section Palustria Dahlstedt. Acta Biol. Cracov. Ser. Bot., 16, 37-84.

MENDIBURU, A. O. AND PELOQUIN, S. J. 1979. Gene-centromere mapping by $4 \mathrm{x}-2 \mathrm{x}$ matings in potato. Theor. Appl. Genet., 54, 177-180.

MOGIE, M. 1992. The Evolution of Asexual Reproduction in Plants. Chapman \& Hall, London.

MULLER, H. J. 1964. The relation between recombination to mutational advance. Mutat. Res., 1, 2-9.

NOGLER, G. A. 1984. Gametophytic apomixis. In: Johri, B. M. (ed.) Embryology of Angiosperms, pp. 475-518. Springer, Berlin.

NOGLER, G. A. 1995. Genetics of apomixis in Ranunculus auricomus. VI. Epilogue. Bot. Helv., 105, 111-115.

OHAD, N., MARGOSSIAN, L., HSU, Y.-C., WILLIAMS, C., REPETTI, P. AND FISHER, R. L. 1996. A mutation that allows endosperm development without fertilization. Proc. Natl. Acad. Sci. U.S.A., 93, 5319-5324.

POWERS, L. 1945. Fertilization without reduction in the guayule (Parthenium argentatum Gray) and a hypothesis as to the evolution of apomixis and polyploidy. Genetics, 30, 323-346.

RAMANNA, M. S. 1979. A re-examination of the mechanisms of $2 \mathrm{n}$ gamete formation in potato and its implications for breeding. Euphytica, 28, 537-561.

RICHARDS, A. J. 1970. Eutriploid facultative agamospermy in Taraxacum. New Phytol., 69, 761-774.

RICHARDS, A. J. 1973. The origin of Taraxacum agamospecies. Bot. J. Linn. Soc., 66, 189-211.

SøRENSEN, T. 1958. Sexual chromosome-aberrants in triploid apomictic Taraxaca. Bot. Tidskr., 54, 1-22.

TAS, I. C. Q. AND VAN DIJK, P. J. 1999. Crosses between sexual and apomictic dandelions (Taraxacum). I. The inheritance of apomixis. Heredity, 83, 707-714. 